\title{
Legal Factors and Psychological Stress of Health Professionals in the Forensic Area: A Systematic Review Protocol
}

João Paulo Nogueira da Silva ( $\sim$ borgesjpsilva@yahoo.com.br)

Universidade Federal do Pará https://orcid.org/0000-0003-4446-5021

Monalisa Pereira Furtado

Universidade Federal do Pará https://orcid.org/0000-0002-2355-7157

Celina Maria Colino Magalhães

Universidade Federal do Pará https://orcid.org/0000-0002-1279-179X

Janari da Silva Pedroso

Universidade Federal do Pará https://orcid.org/0000-0001-7602-834X

\section{Method Article}

Keywords: Mental Health, Forensic Psychiatry, Health Personnel, Psychological stress

Posted Date: July 13th, 2021

DOI: https://doi.org/10.21203/rs.3.rs-705531/v2

License: (c) (i) This work is licensed under a Creative Commons Attribution 4.0 International License. Read Full License 


\section{Abstract}

Background: The illness of mental health workers in the forensic area has multifactorial causes, but among the main ones is the stress resulting from legal factors at work, such as workload; bylaws; wage; promotion; resignation; assignments; safety rules; legislation for the promotion, prevention and protection of health in the workplace; regulation of risky activities, as they significantly vary the health-disease process of health personnel by directly interfering with their work mode and rhythm. Evidence shows that it is the population group more prone to stress, physical and mental exhaustion, and suicide, unlike the rest of the population. It is noteworthy the fact that $90 \%$ of the world population suffers from stress, according to the World Health Organization. Given the growth of primary research on the subject and its importance in the various health outcomes, it is necessary to start processes of compilation and synthesis of this evidence to facilitate understanding of the importance of legal factors as stressors to the work routine of health professionals in the forensic area.

Methods: The studies included will be original qualitative and quantitative research articles. This systematic review protocol will be conducted in accordance with the Cochrane Manual and will follow PRISMA-P guidelines. Searches will take place from August 2021 to October 2021 and will be performed from the following electronic databases: APA PsycNet, Web of Science, Scopus, PubMed, Oxford Journals and ScienceDirect. Two reviewers will obtain eligible articles, published from 1990 to 2020, to assess the quality of each study and extract data. A narrative and qualitative synthesis will be used to analyze the primary results, and choose the articles relevant to the research objective.

Discussion: The results of this review will contribute to a better understanding that stress in the workplace is not restricted to clinical and organizational factors, but also occurs as a result of legal factors. This expanded understanding of the causes of work stress can better support discussions on the reformulation of legislation related to prevention, promotion and recovery of workers' health effectively.

Ethics and dissemination: Ethics committee approval is not required for a systematic review protocol. The results will be published in a peer-reviewed health or social science journal.

\section{Systematic Review Registration: PROSPERO CRD42021225442}

\section{Introduction}

By mental health is understood the state of well-being in which a person performs their skills, deals with the normal stresses of life, works productively and contributes to their community [1]. One of the main factors that affect the balance of mental health is stress, and according to the World Health Organization (WHO) approximately $90 \%$ of the world population is affected by this condition, and that is precisely why this factor is considered to be global epidemic [2;3]. There is a growing concern of countries to build effective public policies in the promotion, prevention and recovery of the mental health of their population in relation to work and public health [4]. 
In the mid-twentieth century, stress was defined as the General Adaptation Syndrome, which is the body's natural defense reaction to adverse situations [5]. From this perspective, stress has the positive dimension, which is eustress, in which the individual is more productive and creative in their adaptive reactions, and the negative dimension, which is distress, a state in which there is excess or lack of adaptation, which leads the individual to express inappropriate responses [6]. At the turn of the $21 \mathrm{st}$ century, stress had a greater incidence in the population and caused demands for psychiatric and psychological services, and came to be defined as a psychological factor that represents a harmful relationship between the individual and the environment, which affects their mental health [7].

In 1990, WHO and PAHO (Pan American Health Organization) began the restructuring of psychiatric care in the region of the Americas, which resulted in the Declaration of Caracas. This document states that the development of psychiatric care in mental health is necessarily linked to the primary care of local health systems [8]. As early as 1991, the United Nations General Assembly reinforced the principles for the protection of people with mental illness and the improvement of health care, with an emphasis on community services and the rights of people with mental illness [9].

To operationalize this restructuring, it was necessary to adapt the state and private sectors of the mental health field to legislative, technical and organizational innovations and, in particular, the approximation of the judicial system to the health system [10]. Bringing these systems together was essential in improving the guarantee of individual freedom and human dignity for the recipient of care, which includes those in custody of forensic psychiatric hospitals.

The forensic psychiatric hospital is part of the field of forensic psychiatry, which in its essence is related to the assessment and treatment of people with mental disorders, who present antisocial or violent behavior, through the interface of mental health and law [11], which may include the correctional perspective [12]. In conjunction with the forensic psychiatric hospital are general psychiatric hospitals, psychiatric wards in district general hospitals and prisons with regard to the European continent [11]; and in North and South America there are the Psychiatric Custody and Treatment Hospitals (HCTP) [13], which together constitute the forensic area of mental health, commonly called forensic psychiatry.

Forensic psychiatry, by adapting to the new guidelines of the WHO, PAHO and the United Nations General Assembly, inserted the multidisciplinary team in mental health throughout its field of action, generally composed of physicians, psychologists, nurses and social workers [14], for an expanded assessment of the health conditions of those in custody in the process of progressive discharge. The professionals of the multidisciplinary mental health team are immersed in the physiological and psychodynamic healthdisease process of work, especially for carrying out medical risk assessments $[15 ; 16 ; 17]$.

The daily performance of medical risk assessments subjects workers of multidisciplinary health teams to high levels of stress, due to experiencing the physical resistance of the custodian to the treatment, as well as violent behavior during personal care [17], emotional state and unstable mental disorders, impulsivity, side effects of medications, severe personality disorder, psychosis, and a history of violent crimes [16]. The high level of stress for long periods can lead to the appearance of pathologies such as panic 
disorder, post-traumatic stress disorder (DSM, 2014) and Burnout [18], which increases the percentage of dissatisfaction with work, medical licenses, chemical dependency, exhaustion, drug addiction and physical-mental exhaustion of these health professionals, which consequently makes the maintenance of forensic psychiatry services for the State more expensive [19].

The forensic psychiatric hospital becomes a sickening workplace, by subsidizing high levels of stress to the multidisciplinary health team, which can cause some mental disorder. In Brazil, the most populous country in Latin America, mental and behavioral disorders are the third leading cause of absence from work, including absenteeism and sick leave [20]. Piolli and Heloani [21], condense the causes of this scenario, the organizational, clinical and legal factors that permeate the health-disease process, which are present from hypercompetitiveness, human disposability to social Darwinism, which intensify the feeling of insecurity, frustration and angst around employment, which can turn into unemployment.

Evidence demonstrates that the health-disease process of forensic health professionals is directly influenced by organizational, clinical and legal factors $[22,23,24]$. Legal factors, such as workload; bylaws; code of ethics; disciplinary process; wage; possibility of promotion and dismissal; assignment definitions; safety rules; legislation for the promotion, prevention and protection of health in the workplace; regulation of risky activities significantly varies the health-disease process of health personnel by directly interfering with their mode and pace of work [15].

The pace of work in the forensic area, as in any work activity, which is ultimately directly influenced by legal factors and the logic of capital, on several occasions goes out of step with the biological and psychological pace of the health professional, when it precarious mental health of the latter [25]. This conflict of rhythms is constant, as legal factors are present in the detailed aspects of the functioning of institutions in the forensic area and influence their entire dynamics, from the professional's mental health, to the types of assessments he performs, instruments used, treatment model to the itinerary of risky activities.

Studies demonstrate that legal factors directly and concomitantly influence clinical and organizational factors in the field of health $[26,27]$. The main systematic reviews analyzed these three factors separately, with a greater focus on the clinical and organizational [28], however, the interest in the influence of the legal factor in the work environment and in the mental health status of professionals has gained increasing importance. This scenario of interest can be attributed to the fact that there is growing evidence that health professionals, especially those in the field of mental health, are at increased risk of mental disorders [29, 30], burnout [31, 32] and suicide [33] than the rest of the population.

The causes of stress among mental health professionals are not easy to identify. Studies have evaluated two hypotheses: that the organizational environment of forensic psychiatry attracts a specific group of people and that the difficulty could be in the clinical condition of the patients they work with [34, 35]. However, these studies did not demonstrate that organizational and clinical aspects are more important than legal factors in causing stress. 
The study by Deary, Agius and Sadler [35] also demonstrates that personality differences, such as neuroticism, affability and conscientiousness, between psychiatrists, general practitioners and surgeons influence less stress than the workload. The study by Guppy and Gutteridge [34] ends up showing that job stress among British nurses was related both to relationships in the team and to technical and financial resources determined by legislation, to the detriment of the clinical condition of the patient's imminent death.

Although these studies report stress on mental health professionals, it must be said that such analyzes, for the most part, focus only on clinical and organizational aspects to the detriment of legal aspects that are part of the health-disease process. To contribute to the understanding of the role and functions of legal factors in the stress of health professionals and thus fill this gap, this systematic review will be carried out in order to describe how the legal factors of work are related to the psychological stress of professionals of health in the forensic area.

\section{Objectives}

The main objective is to describe how the legal factors of work are related to the psychological stress of health professionals in the forensic area. Secondarily, the objective is to identify the main legal factors of work related to stress in this population.

\section{Methods And Analysis}

This systematic review will be carried out following the Cochrane Manual for Systematic Reviews [36] and the data obtained will be reported from the guidelines and recommendations of the 'Preferred Reporting Items for Systematic Reviews and Meta-Analytical Protocols' (PRISMA-P) model [37]. Citations and references will be managed in the Mendeley software and data will be extracted and reported in a flowchart. This systematic review protocol was registered in the International Prospective Registry of Systematic Reviews - PROSPERO (registration number: CRD42021225442).

\section{Eligibility Criteria}

\section{Types of studies}

The types of studies included will be primary case study, ethnographic, observational (cohort and casecontrol), clinical and cross-sectional studies, both in qualitative and quantitative perspectives.

\section{Types of Participants}

The articles retrieved from the databases will have health professionals working in the forensic care network as the research population.

\section{Patient and Public Involvement}

No patient involved. 


\section{Types of outcome measures}

Their results will have to present the outcome or report that describes how the relationship between the legal factors of work and the psychological stress of this population occurs. The review will also consider, as an outcome measure, studies that identify the legal factor in psychological stress without a full description of the influence relationship.

\section{Search strategies}

\section{Electronic searches}

We chose to search through the coffee system (Federated Academic Community), because it offers complete access to the main databases in the world, which expands the search field and its quality. The electronic databases will be APA PsycNet (American Psychological Association), Web of Science (Clarivate Analytics), Scopus (Elsevier), PubMed, Oxford Journals (Oxford University Press) and ScienceDirect (Elsevier).

\section{Research vocabular}

The controlled vocabulary MeSH (Medical Subject Headings) will be used for the search strategy and for the establishment of the following keywords: Mental Health; Forensic Psychiatry; Health Personnel; Psychological stress. In addition, the Boolean operator "AND" will be used to specify the syntactic structure of the search terms, which have been tested and established for all databases: Mental Health AND Forensic Psychiatry; Mental Health AND Health Personnel; Mental Health AND Psychological stress; Forensic Psychiatry AND Health Personnel; Forensic Psychiatry AND Psychological stress; Health Personnel AND Psychological stress.

\section{Search criteria}

The writing language of the selected articles will be Portuguese, Spanish and English with the aim of gathering as many studies as possible. Studies referring to the period between 1990 and 2020 will be sought, as from that period onwards there were legislative changes in the international context that restructured health care in the forensic area.

The study selection criteria will be: type of study; language; year of publication; article format; full access to the study published through the CAFe system; answer the survey question. Gray literature (dissertations, books, chapters, reports, conference material, opinion articles, comments and reviews) will be excluded from the review, as this type of literature may contain anecdotal or reflective evidence based on primary studies that distort the results found. in research due to the possible absence of peer review.

\section{Study records}

\section{Selection process}


All study search results will be imported into Mendeley software to manage data and eliminate duplicate articles. Initially, the titles and abstracts of all retrieved studies will be selected by a reviewer to identify potentially eligible studies. A second reviewer will independently screen the articles selected by the first reviewer, with a margin of disagreement of $10 \%$, any discrepancies above this percentage will be resolved by a more experienced third reviewer. Full manuscripts will be obtained for all studies selected as potentially relevant. Articles will be subsequently selected for inclusion based on the eligibility criteria.

\section{Data Extraction Process}

A data extraction table will be produced in Microsoft Excel and the Agency for Healthcare Research and Quality Systematic Review Data Repository (SRDRPlus) which is extremely useful in extracting, managing and archiving online data during systematic reviews. These tools will be essential later to thoroughly check all steps of the review for replicability.

The information extracted will include: types of studies (case, ethnographic, cohort and case-control and cross-sectional studies); objective and purposes of the research process; characteristics of participants; context (general psychiatric hospitals, psychiatric wards in district general hospitals, prisons and Hospitals for Custody and Psychiatric Treatment); methods of each study (design, reported and observed methodological limitations, data collection and analysis methods); primary and secondary outcomes and the main conclusions of the study.

After extracting the data, two of the reviewers will deal with disagreements through consensus and, if necessary, a third reviewer will be involved. The main themes identified by the authors of the articles will be briefly summarized at this stage, before the meta-synthesis of the articles. The selection procedure will be documented in accordance with PRISMA-P guidelines and reported in a flowchart.

\section{Quality assessment}

The assessment of the quality of qualitative studies will be assessed using the Critical Appraisal Skills Program (CASP) [38] tool, which has the following checklist: Qualitative Studies Checklist; Cohort Study Checklist and Case Control Study Checklist. The studies will be independently evaluated by two researchers. To resolve any divergences in the score of the articles, the opinion of a third researcher will be consulted.

\section{Data synthesis}

Data will be synthesized from the thematic synthesis [39]. The findings of the studies that will be used for analysis include all text present in their results sections. The synthesis method involves three steps: the first consists of analyzing the text line by line, to identify the results as each study is read. The second stage involves the grouping of descriptive themes through the process of identifying similarities and differences in the contents of the results section, in a hierarchical structure, using the NVivo ${ }^{\circledR}$ software. All sections of final sample results will be translated into English, as the NVivo® software can only process single language texts. The final step involves using the descriptive themes to answer the review 
question and, thus, generate content and information that go beyond the initial synthesis of the findings of the primary articles.

The entire process will be done by two reviewers, independently, who will then discuss their results among themselves to verify issues that may still emerge. This process will be repeated until the themes generated sufficiently represent the results of the studies and answer the review question.

\section{Ethics and dissemination}

The review will seek and evaluate primary sources obtained from previous research; therefore, no formal ethics committee approval is required. The results of the systematic review will be published in an international peer-reviewed journal. The authors will plan presentations at possible national or international conferences to disseminate the results among the academic community.

\section{Discussion}

The psychological stress of mental health professionals in the forensic area has been increasingly explored in health research, especially with evidence-based practices (EBP), a research modality that is emerging in the health field. The results of this review will contribute to the understanding that stress in the workplace is not restricted to clinical and organizational factors, but also occurs as a result of legal factors. Gathering these primary data is important for possible construction of improvements in legal labor factors in relation to the mental health of forensic professionals, through EBP [40], as the estimated cost of stress-related illnesses in the United States of America, which concentrates the largest population of health professionals and industry in general, is approximately $\$ 13,000.00$ per employee per year [41].

With a view to reducing costs with costly treatments and building prevention and mental health promotion policies for forensic workers, there is a need to expand the analysis of stressors. Classic studies in relation to stress in the work environment focus on the organizational and clinical aspects, to the detriment of the analysis and direct influence of legal factors on workers' health [23].

\section{Declarations}

\section{Ethics approval}

Ethics committee approval is not required for a systematic review protocol. The results will be published in a peer-reviewed health or social science journal.

\section{Consent for publication}

Not applicable.

\section{Competing interests}


None declared.

\section{Availability of data and materials}

The datasets generated and analyzed during the current study are publicly available on SRDRPlus.

\section{Funding}

This systematic review is supported by the Universidade Federal do Pará, Brasil/Pró-Reitoria de Pesquisa e Pós-graduação (PROPESP) and the Coordenação de Aperfeiçoamento de Pessoal de Nível Superior CAPES (financed code 001).

\section{Authors' Contributions}

JS contributed to the design of this systematic review. The protocol manuscript was written by JS and MF and reviewed by JP and CM. All authors developed search and evaluation strategies. All authors have read and critically commented on each version of the manuscript. Finally, all authors approved the final manuscript.

\section{Acknowledgements}

The authors would like to thank all those who contributed to the elaboration of this protocol.

\section{References}

1. World Health Organization. Mental health; strengthen our response. [Internet] Genebra: WHO; 2018 [cited 2021 July 10]. Available from: https://www.who.int/news-room/fact-sheets/detail/mental-healthstrengthening-our-response

2. Batista $K$ de M, Bianchi ERF. Estresse do enfermeiro em unidade de emergência. Rev Lat Am Enfermagem. 2006;14(4):534-9.

3. I CM, Coutinho A, Guimarães DA, I ZM. Qualidade de Vida e Estresse Ocupacional em Estudantes de Medicina. Rev Bras Educ Med. 2012;36(4):489-98.

4. Mendes SS, Ferreira LRC, De Martino MMF. Identificação dos níveis de stress em equipe de atendimento pré-hospitalar móvel. Estud Psicol. 2011;28(2):199-208.

5. Selye H. Stress, a tensão da vida. São Paulo: Ibrasa.1959. 416 p.

6. Filgueiras JC, Hippert MIS. A polêmica em torno do conceito de estresse. Psicol Ciência e Profissão. 1999;19(3):40-51.

7. Borsoi ICF. Da relação entre trabalho e saúde à relação entre trabalho e saúde mental. Psicol Soc. 2007;19(spe):103-11. 
8. World Health Organization. Relatório Mundial da Saúde.1. ed. Lisboa: Climepsi Editores; 2002. 206 p.

9. United Nations. The protection of persons with mental illness and the improvement of mental health care. In: UN General Assembly resolution A/RES/46119. 1991. p. 0-5.

10. Morrissey JP, Fagan JA, Cocozza JJ. New models of collaboration between criminal justice and mental health systems. Am J Psychiatry. 2009;166(11):1211-4.

11. Niveau G, Welle I. Forensic psychiatry, one subspecialty with two ethics? A systematic review. Vol. 19, BMC Medical Ethics. 2018.

12. Arboleda-Flórez J. Forensic psychiatry: contemporary scope, challenges and controversies. World Psychiatry. 2006;5(2):87-91.

13. dos Santos ALG, de Farias FR, Pinto D de S. Por uma sociedade sem hospitais de custódia e tratamento psiquiátrico. Hist Ciencias, Saude - Manguinhos. 2015;22(4):1215-30.

14. Scanlan JN, Still M. Relationships between burnout, turnover intention, job satisfaction, job demands and job resources for mental health personnel in an Australian mental health service. BMC Health Serv Res. 2019;19(1):1-11.

15. Da Silva EV, Ribeiro MC, De Souza MCS. The performance of health professionals in a custody and psychiatric treatment hospital: The perspective of the psychosocial rehabilitation. Brazilian J Occup Ther. 2018;26(2):315-27.

16. Buchanan A, Grounds A. Forensic psychiatry and public protection. Br J Psychiatry. 2011;198(6):4203.

17. Kennedy HG. Therapeutic uses of security: Mapping forensic mental health services by stratifying risk. Adv Psychiatr Treat. 2002;8(6):433-43.

18. Harrad R, Sulla F. Factors associated with and impact of burnout in nursing and residential home care workers for the elderly. Acta Biomed. 2018;89(7S):60-9.

19. Moore JE, Bumbarger BK, Cooper BR. Examining adaptations of evidence-based programs in natural contexts. J Prim Prev. 2013;34(3):147-61.

20. Silva EP e. A escuta do trabalhador estressado enquanto estratégia de aprimoramento da formação profissional. Aletheia. 2009;(29):43-56.

21. Piolli E, Heloani JR. Trabalho e subjetividade na nova configuração laboral: quem paga a conta?. Germinal: Marxismo e Educação em Debate. 2014; 6:118- 129.

22. Jaegers LA, Matthieu MM, Werth P, Ahmad SO, Barnidge E, Vaughn MG. Stressed Out: Predictors of Depression Among Jail Officers and Deputies. Prison J. 2020;100(2):240-61. 
23. Ross T, Querengässer J, Fontao MI, Hoffmann K. Predicting discharge in forensic psychiatry: The legal and psychosocial factors associated with long and short stays in forensic psychiatric hospitals. Int J Law Psychiatry. 2012;35(3):213-21.

24. Moran MJ, Fragala MR, Wise BF, Novak TL. Factors affecting length of stay on maximum security in a forensic psychiatric hospital. Int J Offender Ther Comp Criminol. 1999;43(3):262-74.

25. Silva G de N e. Recognizing stress at work: a critical appraisal. Gerais Rev Interinstitucional Psicol. 2019;12(1):51-61.

26. Boran A, Shawaheen M, Khader Y, Amarin Z, Hill Rice V. Work-related stress among health professionals in northern Jordan. Occup Med (Chic III). 2012;62(2):145-7.

27. Pelisoli C, Moreira ÂK, Kristensen $\mathrm{CH}$. Avaliação da satisfação e do impacto da sobrecarga de trabalho em profissionais de saúde mental. Mental. 2007;V(9):63-78.

28. Al Marashi TM, Al Zghool MM. Factors Influencing Job Performance among Nurses Who are Working in Saudi Mental Health Hospitals. Am J Nurs Res. 2018;6(2):67-81.

29. Wall TD, Bolden RI, Borrill CS, Carter AJ, Golya DA, Hardy GE, et al. Minor psychiatric disorder in NHS trust staff: Occupational and gender differences. Br J Psychiatry. 1997;171(DEC.):519-23.

30. Fagin L, Brown D, RMN HB, Leary J, Carson J. The Claybury community psychiatric nurse stress study: is it more stressful to work in hospital or the community? Vol. 22, Journal of Advanced Nursing. 1995. p. 347-58.

31. Prosser D, Johnson S, Kuipers E, Szmukler G, Bebbington P, Thornicroft G. Perceived sources of work stress and satisfaction among hospital and community mental health staff, and their relation to mental health, burnout and job satisfaction. J Psychosom Res. 1997;43(1):51-9.

32. Olkinuora M, Asp S, Juntunen J, Kauttu K, Strid L, Äärimaa M. Stress symptoms, burnout and suicidal thoughts in Finnish physicians. Soc Psychiatry Psychiatr Epidemiol. 1990;25(2):81-6.

33. Lindeman $S$, Läärä $E$, Hakko H, Lönnqvist J. A systematic review on gender-specific suicide mortality in medical doctors. Br J Psychiatry. 1996;168(MAR.):274-9.

34. Guppy A, Gutteridge T. Job satisfaction and occupational stress in UK general hospital nursing staff. Work Stress. 1991;5(4):315-23.

35. Deary IJ, Agius RM, Sadler A. Personality and stress in consultant psychiatrists. Int J Soc Psychiatry. 1996;

36. Higgins JPT, Thomas J, Chandler J et al, editors. Cochrane Handbook for Systematic Reviews of Interventions version 6.1 (updated September 2020). Cochrane, 2020. 
37. Moher $D$, Shamseer $L$, Clarke $M$, et al. Preferred reporting items for systematic review and metaanalysis protocols (PRISMA-P) 2015 statement. Syst Rev. 2015;4:1.

38. Critical Appraisal Skills Programme. CASP Qualitative Studies Checklist. [Internet]. Oxford: CASP; 2018 [cited 2021 July 10]. Available from: https://casp-uk.net/casp-tools-checklists/

39. Thomas J, Harden A. Methods for the thematic synthesis of qualitative research in systematic reviews. BMC Med Res Methodol. 2008;8:1-10.

40. Melnik T, Atallah ÁN. Psicologia baseada em evidencias: provas clinicas da efetividade da psicoterapia. São Paulo: Santos Editora; 2011. 366 p.

41. Bruhn J, Chesney A, Salcido R. Health and organizational issues in managing a multicultural work force. Family and Community Health. 1995;18(2):1-8. 